\title{
Bench-to-bedside review: Chloride in critical illness
}

\author{
Nor'azim Mohd Yunos', Rinaldo Bellomo ${ }^{1 *}$, David Story² and John Kellum³
}

\begin{abstract}
Chloride is the principal anion in the extracellular fluid and is the second main contributor to plasma tonicity. Its concentration is frequently abnormal in intensive care unit patients, often as a consequence of fluid therapy. Yet chloride has received less attention than any other ion in the critical care literature. New insights into its physiological roles have emerged together with progress in understanding the structures and functions of chloride channels. In clinical practice, interest in a physicochemical approach to acid-base physiology has directed renewed attention to chloride as a major determinant of acid-base status. It has also indirectly helped to generate interest in other possible effects of disorders of chloraemia. The present review summarizes key aspects of chloride physiology, including its channels, as well as the clinical relevance of disorders of chloraemia. The paper also highlights current knowledge on the impact of different types of intravenous fluids on chloride concentration and the potential effects of such changes on organ physiology. Finally, the review examines the potential intensive care unit practice implications of a better understanding of chloride.
\end{abstract}

\section{Introduction}

Chloride is the major strong anion in blood - accounting for approximately one-third of plasma tonicity, for 97 to $98 \%$ of all strong anionic charges and for two-thirds of all negative charges in plasma [1]. The amount of attention chloride receives in critically ill patients, however, is limited and much less than other routinely measured electrolytes. For example, the PubMed search term 'hyperchloremia' generates 181 citations while 'hypernatremia' and 'hypercalcemia' generate 2,481 and 15,518 citations, respectively [2]. It is therefore little

*Correspondence: rinaldo.bellomo@austin.org.au

'Department of Intensive Care, Austin Hospital, Heidelberg, Melbourne, VIC 3084, Australia

Full list of author information is available at the end of the article surprise that chloride is sometimes referred to as the forgotten electrolyte [3].

Progress in our understanding of acid-base and chloride channel physiology, however, challenges the notion that neglecting chloride is justified. This progress can be traced to more than 100 years ago with the observation of a poisonous effect of sodium chloride solutions on nerve muscle preparation [4], followed by recognition of metabolic acidosis after saline infusion in the 1920s [5], and the concept of hyperchloraemic acidosis [6,7]. In the 1990s, hyperchloraemic acidosis became more thoroughly studied [8-15] as the physicochemical approach (Stewart approach) to acid-base analysis $[16,17]$ began to receive wider acceptance. Within the Stewart approach, chloride is the dominant negative strong ion in plasma and a key contributor to the strong ion difference (SID), one of the three independent variables that determine the hydrogen ion concentration. Hyperchloraemia was thus finally seen as important for the pathogenesis of metabolic acidosis. This change in perception may be particularly relevant to intensivists, given that hyperchloraemia appears relatively common in intensive care unit (ICU) patients [18]. At the same time, our knowledge of chloride channels has increased in the past decade with new discoveries of their crystal structures, physiological roles and their association with human diseases [19-21].

All of these changes in attitude and knowledge support the argument that the role of chloride in the ICU deserves more attention. In the present review, therefore, we wish to focus on the following five aspects: the fundamentals of chloride distribution and measurement, an outline of Stewart's physicochemical approach and the significance of chloride as a strong ion, chloride's roles through review of its channels and chloride regulation by the gut and kidney, chloride manipulation in the ICU and potential effects of disorders of chloraemia in the critically ill, and the implications of all the above on current critical care practice and research.

\section{Chloride distribution and measurement}

The main source of chloride is dietary sodium chloride, intake of which is 7.8 to $11.8 \mathrm{~g} /$ day for adult men and 5.8 to $7.8 \mathrm{~g} /$ day for adult women in the United States [22] equivalent to 133 to $202 \mathrm{mmol}$ and 99 to $133 \mathrm{mmol}$ 

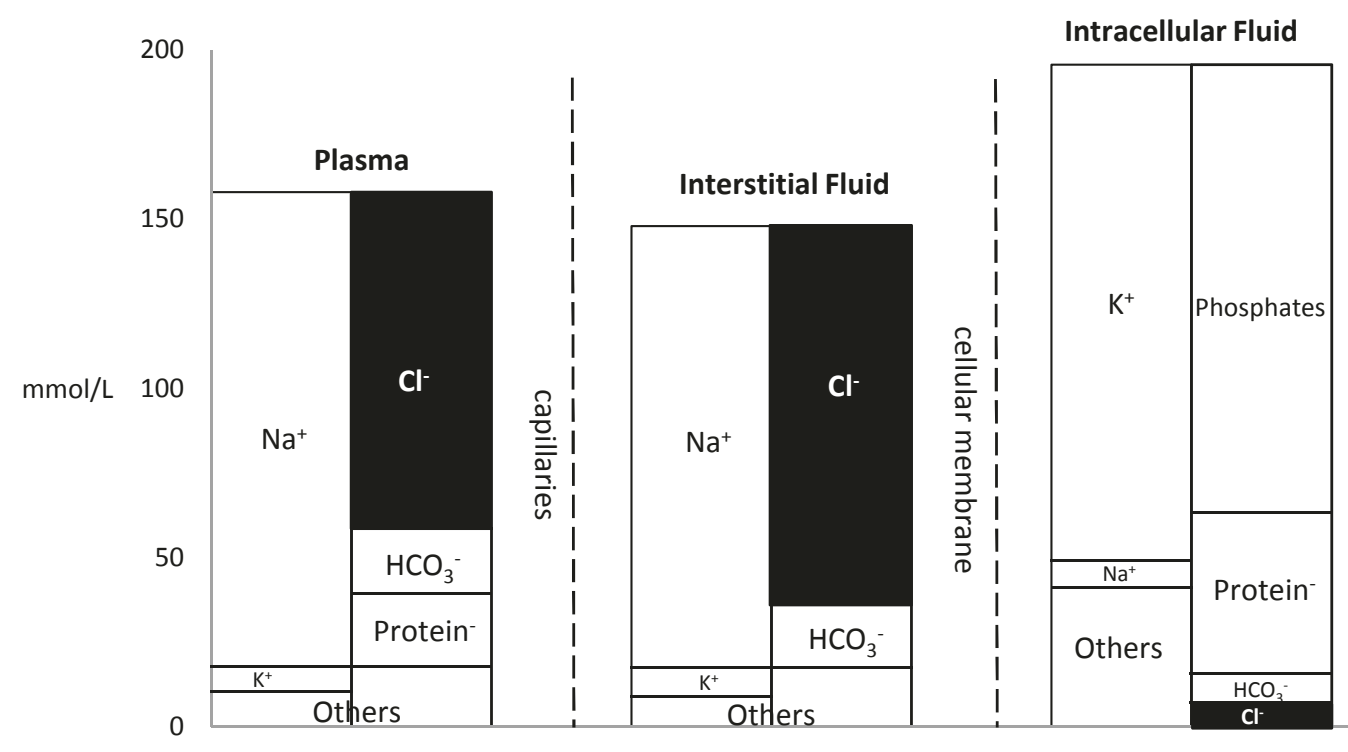

Figure 1. Chloride distribution in the major body fluid compartments.

chloride, respectively (chloride molar mass, $35.5 \mathrm{~g} / \mathrm{mol}$ ). This intake approximates to administration of 0.5 to 1.3 litres per day of $0.9 \%$ saline (chloride, $154 \mathrm{mmol} / \mathrm{l}$ ).

The chloride distribution in the three major body fluid compartments - plasma, interstitial fluid (ISF) and intracellular fluid - is shown in Figure 1. Chloride is the most abundant anion in plasma and ISF, the two compartments that make up extracellular fluid. Its concentrations in these two compartments differ slightly as a result of capillary impermeability to proteins, especially albumin. The asymmetric distribution of anionic proteins between plasma and ISF results in the Gibbs-Donnan effect, with the ISF chloride concentration 5 to $10 \%$ greater than in plasma [23]. Most cells have intracellular concentrations of about $10 \mathrm{mmol} / \mathrm{l}$ [23], but the range varies widely from $2 \mathrm{mmol} / \mathrm{l}$ in skeletal muscle to $90 \mathrm{mmol} / \mathrm{l}$ in erythrocytes [24].

It is important for clinicians to recognize that the measured plasma chloride concentration may differ between assays. With paired samples, the mean difference (bias) in plasma chloride concentration between central laboratory and point-of-care assays can be $1.0 \mathrm{mmol} / \mathrm{l}$ (95\% limits of agreement, -6.4 to $4.6 \mathrm{mmol} / \mathrm{l}$ ) [25]. While decreased plasma albumin contributes to differences in sodium assays, however, albumin changes have little effect on chloride assays [26]. Further, while the reference range for central laboratory assays is often quoted as 97 to $107 \mathrm{mmol} / \mathrm{l}$, some machines used in central laboratories have a reference range of 100 to $110 \mathrm{mmol} / \mathrm{l}$. Using paired samples (unpublished results), when our central laboratory changed from a Hitachi to a Beckman machine, we found a bias in plasma chloride of
$2.0 \mathrm{mmol} / \mathrm{l}$ (95\% limits of agreement, -1.7 to $5.6 \mathrm{mmol} / \mathrm{l})$. While these differences are important in assessing chloride alone, they will also affect derived variables including the anion gap [26], the corrected anion gap [27], the strong ion gap [28], and the sodium chloride difference [29].

\section{Chloride and the Stewart approach}

The surge in the number of studies on hyperchloraemic acidosis coincided with the emergence of the Stewart physicochemical approach, with many comparisons of $0.9 \%$ saline and colloids suspended in saline solutions with more balanced, lower chloride, intravenous solutions (Tables 1 and 2). Compared with lactated Ringer's solution in patients undergoing major gynaecological surgery, infusion of $30 \mathrm{ml} / \mathrm{kg} /$ hour of $0.9 \%$ saline caused a significant acidosis within 2 hours [9]. This finding, coupled with higher chloride measurement in the saline group, was replicated in a number of other studies $[10,12,14,15,30]$. Significant negative correlation between hyperchloraemia and base excess was further shown in patients undergoing surgery for more than 4 hours [10] and in an audit of ICU patients [18].

An understanding of Stewart's approach may help to understand how chloride might affect the hydrogen ion concentration $\left[\mathrm{H}^{+}\right][16,17]$. Through quantitative analysis that satisfies the principles of electroneutrality, dissociation equilibria and conservation of mass, this approach argues that determination of $\left[\mathrm{H}^{+}\right]$depends on three independent variables: the SID, the partial pressure of carbon dioxide, and the total weak acid concentration. A change in any of these three variables, and not in 
Table 1. Electrolyte composition of commonly used crystalloids

\begin{tabular}{|c|c|c|c|c|c|}
\hline & & & entration $(\mathrm{mm}$ & & \\
\hline & Plasma & $0.9 \% \mathrm{NaCl}$ & Hartmann's & Plasma-Lyte $148^{\circ}$ & Sterofundin ${ }^{\oplus}$ \\
\hline Sodium & 140 & 154 & 131 & 140 & 140 \\
\hline Potassium & 5 & 0 & 5 & 5 & 4 \\
\hline Chloride & 100 & 154 & 111 & 98 & 127 \\
\hline Calcium & 2.2 & 0 & 2 & 0 & 2.5 \\
\hline Magnesium & 1 & 0 & 1 & 1.5 & 1 \\
\hline Bicarbonate & 24 & 0 & 0 & 0 & 0 \\
\hline Lactate & 1 & 0 & 29 & 0 & 0 \\
\hline Acetate & 0 & 0 & 0 & 27 & 24 \\
\hline Gluconate & 0 & 0 & 0 & 23 & 0 \\
\hline Maleate & 0 & 0 & 0 & 0 & 5 \\
\hline
\end{tabular}

Plasma-Lyte $148^{\oplus}$ from Baxter International (Deerfield, IL, USA). Sterofundin ${ }^{\oplus}$ from B Braun (Melsungen, Germany).

Table 2. Electrolyte composition of commonly used colloids

\begin{tabular}{|c|c|c|c|c|c|c|}
\hline & \multicolumn{6}{|c|}{ Concentration (mmol/l) } \\
\hline & Plasma & Gelofusine $^{\circledast}$ & Albumex ${ }^{\oplus}$ & $\begin{array}{c}\text { Voluven }^{\circledast} \\
\text { (HES 6\% 130/0.4)/ } \\
\text { Venofundin } \\
\text { (HES 6\% 130/0.42) }\end{array}$ & $\begin{array}{c}\text { Hextend }^{\oplus} \\
\text { (HES 6\% 130/0.4) }\end{array}$ & $\begin{array}{c}\text { Tetraspan } \\
\text { (HES 6\% 130/0.42) }\end{array}$ \\
\hline Sodium & 140 & 154 & 140 & 154 & 143 & 140 \\
\hline Potassium & 5 & 0 & 0 & 0 & 3 & 4.0 \\
\hline Chloride & 100 & 125 & 128 & 154 & 124 & 118 \\
\hline Calcium & 2.2 & 0 & 0 & 0 & 2.5 & 2.5 \\
\hline Magnesium & 1 & 0 & 0 & 0 & 0.5 & 1.0 \\
\hline Bicarbonate & 24 & 0 & 0 & 0 & 0 & 0 \\
\hline Lactate & 1 & 0 & 0 & 0 & 28 & 0 \\
\hline Acetate & 0 & 0 & 0 & 0 & 0 & 24 \\
\hline Malate & 0 & 0 & 0 & 0 & 0 & 5 \\
\hline Octanoate & 0 & 0 & 6.4 & 0 & 0 & 0 \\
\hline
\end{tabular}

HES, hydroxyethyl starch. Gelofusine ${ }^{\oplus}$, Venofundin ${ }^{\oplus}$ and Tetraspan ${ }^{\oplus}$ from B Braun (Melsungen, Germany). Albumex ${ }^{\oplus} 4$ from CSL Limited (Broadmeadows, Victoria, Australia). Voluven ${ }^{\oplus}$ from Fresenius-Kabi (Bad Homburg, Germany). Hextend ${ }^{\oplus}$ from BioTime Inc. (Berkeley, CA, USA).

bicarbonate, will change the acid-base balance. Bicarbonate becomes a marker and not a mechanism, a major difference between the Stewart approach and the traditional Henderson-Hasselbalch approach.

In the traditional approach, bicarbonate independently determines $\mathrm{pH}$ as reflected by the Henderson-Hasselbalch equation:

$$
\mathrm{pH}=\mathrm{pK}+\log \left(\left[\mathrm{HCO}_{3}^{-}\right] /\left[\mathrm{CO}_{2}\right]\right)
$$

Under the Stewart approach, however, bicarbonate is just one of the various dependent ions. Whether the Stewart approach more truly reflects the biochemical events at work during acid-base disorders remains controversial. However, its practical utility has been repeatedly shown $[11,31]$.
Together with other completely dissociated strong ions, chloride determines the SID:

$$
\mathrm{SID}=(\mathrm{Na}+\mathrm{K}+\mathrm{Mg}+\mathrm{Ca})-(\mathrm{Cl}+\text { lactate })
$$

Quantitatively, a change in the strong ion composition leading to lower SID will increase $\left[\mathrm{H}^{+}\right]$while an increase in SID will decrease $\left[\mathrm{H}^{+}\right]$. Hyperchloraemic acidosis therefore causes acidosis by decreasing SID and not through hyperchloraemia alone. This notion is supported by data demonstrating a stronger association between SID and bicarbonate than that between chloride and bicarbonate [31].

Hyperchloraemic acidosis is now increasingly described in terms of its SID nature, including the contribution of the strong ion gap or unmeasured anions 
Table 3. Examples of chloride channels

\begin{tabular}{|c|c|c|}
\hline Channel & Mechanism of regulation & Physiological role \\
\hline CFTR channels & Cyclic AMP-dependent phosphorylation & $\begin{array}{l}\mathrm{Cl}^{-} \text {secretion in airways, submucosal glands, pancreas, intestine } \\
\text { and testis; } \mathrm{Cl}^{-} \text {absorption in sweat glands }\end{array}$ \\
\hline CIC-1 channels & Depolarization & $\begin{array}{l}\mathrm{Cl}^{-} \text {conductance in skeletal muscle; repolarization after action } \\
\text { potential }\end{array}$ \\
\hline CIC-2 channels & Hyperpolarization and cell swelling & $\mathrm{Cl}^{-}$homeostasis in neurons \\
\hline Calcium-activated chloride channels & Cystosolic $\mathrm{Ca}^{2+}$ & $\begin{array}{l}\mathrm{Cl}^{-} \text {transport in retinal pigment epithelium; } \mathrm{Cl}^{-} \text {secretion in } \\
\text { epithelia, neurons, cardiac muscles and erythrocytes; smooth } \\
\text { muscle contraction }\end{array}$ \\
\hline $\mathrm{GABA}_{\mathrm{A}}$ channels & $\mathrm{GABA}_{\mathrm{A}}$ & Inhibition of synaptic transmission in the brain \\
\hline Glycine channels & Glycine, $\beta$-alanine and taurine & Inhibition of synaptic transmission in the spinal cord \\
\hline Volume-sensitive chloride channels & Cell volume changes & Restoration of cell volume \\
\hline
\end{tabular}

CFTR, cystic fibrosis transmembrane conductance regulator; CIC, voltage-gated chloride channel; GABA, $\gamma$-aminobutyric acid.

[32,33]. A detailed explanation of these concepts is beyond the scope of the present review.

At the other end of the spectrum, alkalosis may thus occur with both hypochloraemia and hyperchloraemia, with the latter occurring in the presence of greater hypernatraemia (greater SID) [34]. This again highlights the importance of relative rather than absolute chloraemia. In a study of patients with chronic obstructive pulmonary disease, subjects were found to have hypochloraemia without significant changes in plasma sodium, resulting in a higher SID and subsequent alkalosis [35]. This interestingly concurs with an animal study showing increased renal chloride excretion during hypochloraemia of respiratory acidosis [36].

\section{Chloride channels}

For years, knowledge of chloride channels lagged behind the better known sodium, potassium and calcium channels [19]. Several milestones in the field of ion channels - such as cloning of the cystic fibrosis transmembrane regulator in 1989 , cloning of the first voltagegated chloride channel in 1990 and, more recently, discovery of the crystal structure of chloride channels [19-21] - have altered this scenario. These anion channels are no longer merely unimportant leaks associated with cation channels in the excitable cells [37].

Examples of the different subtypes of these channels, categorised based on their different regulations and roles, are presented in Table 3. Of these subtypes, the cystic fibrosis transmembrane conductance regulator and the ligand-gated chloride channels, activated by $\mathrm{GABA}_{\mathrm{A}}$ and glycine, are probably best known to ICU clinicians. The other subtypes are, nevertheless, no less important. Voltage-gated chloride channels come from nine different genes with a unique dimeric, double-pore (doublebarrelled) structure [20,21]. The structure discovery and further exploration of their molecular mechanisms are seen as frontiers towards greater application of chloride channel manipulation in medicine. Recent insights into these voltage-gated chloride channels have already showed their significant neurological $[38,39]$ and gastrointestinal [40] connections. Calcium-activated chloride channels, on the other hand, are found in various cell types, including epithelial cells, neurons, cardiac cells, smooth muscles and blood cells [21]. They are activated by cytoplasmic calcium elevation following a wide range of stimuli, which include cholinergic activation of glandular secretory epithelium and pain in the dorsal root ganglia neurons [37]. Finally, volume-sensitive chloride channels are an essential element of cell volume regulation. Exposure to hypotonic media stimulates chloride ion efflux through these channels, leading to equilibrium with extracellular tonicity; restoring the cell volume in the process [21]. This cellvolume decrease is now believed to have a role in apoptotic cell death [41], a phenomenon of interest in sepsis [42].

\section{Chloride regulation by the gut and kidney}

Gastrointestinal secretions are rich in chloride, with gastric secretions the predominant source. In the stomach, chloride secreted by apical chloride channels in parietal cells will match hydrogen ions released by the $\mathrm{H}^{+} / \mathrm{K}^{+}$ATPase antiporter pumps (proton pumps), forming hydrochloric acid. Basal output of this acid is in the range 0 to $11 \mathrm{mmol} /$ hour, increasing to 10 to $63 \mathrm{mmol} /$ hour with meals [43]. This load of acid, and thus chloride, is regulated by synergistic activities of histamine, gastrin and acetylcholine.

Chloride is also the main electrolyte driving fluid secretion throughout the intestinal epithelium. Paracellular movement of sodium that accompanies transepithelial chloride secretion results in luminal sodium chloride, which forms the osmotic pressure for water movement with secretions of 8 1/day [44], which are largely reabsorbed throughout the intestinal tract.

Chloride is primarily excreted by the kidney. An average of $19,440 \mathrm{mmol}$ is filtered through the kidneys 


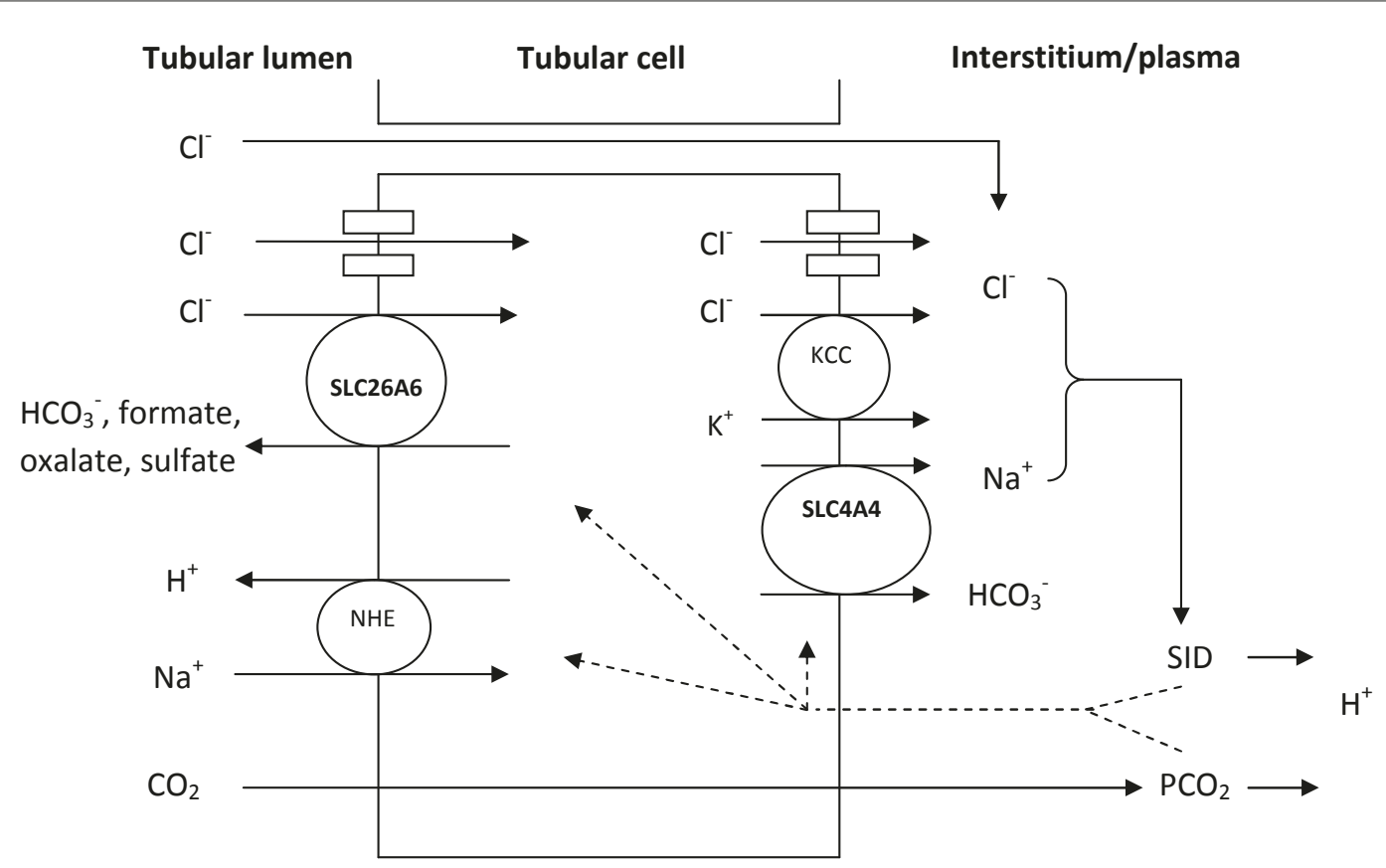

Figure 2. Integration of proximal convoluted tubule chloride transport mechanisms with strong ion difference and partial pressure. Chloride is reabsorbed from passive paracellular transport, conductance and active coupled transport at both apical and basolateral membranes. The strong ion difference (SID) in the plasma, together with the partial pressure of carbon dioxide $\left(\mathrm{PCO}_{2}\right)$, regulates these transport activities and determines the hydrogen ion concentration. $\mathrm{KCC}_{1} \mathrm{~K}^{+} \mathrm{Cl}^{-}$co-transporter; $\mathrm{NHE}, \mathrm{Na}^{+} \mathrm{H}^{+}$exchanger; SLC26A6, solute carrier 26A6; SLC4A4, solute carrier $4 \mathrm{~A} 4$.

every day, with $99.1 \%$ being reabsorbed, leaving only $180 \mathrm{mmol}$ excreted per day [45]. Most of the reabsorption occurs in the proximal tubule, by passive reabsorption, ion conductance or active coupled transport with other ions [46]. Chloride reabsorption involves members of the solute carrier (SLC) gene families SLC26 and SLC24. These two gene families are expressed in various parts of the kidney, particularly in key components of renal acidbase regulation; that is, renal proximal tubules and intercalated cells of distal nephron. The intercalated cells are further differentiated into type A (alpha) cells that excrete protons and type $\mathrm{B}$ (beta) cells that secrete bicarbonate and reabsorb chloride [47]. The transport activities of the two SLC families underline the role of chloride in renal acid-base regulation.

The SLC26 family are primarily chloride-anion exchangers; exchanging sulphate, iodide, formate, oxalate, hydroxyl ion and bicarbonate anions [47]. They include SLC26A6 in the proximal tubule that mediates apical chloride-anion exchange, and SLC26A4 (pendrin) in the distal nephron that mediates chloride-anion exchange across the luminal membrane of type B intercalated cells.

The SLC4 solute carriers, on the other hand, predominantly function as chloride-bicarbonate and anion exchangers and sodium-bicarbonate co-transporters (NBC). Examples are SLC4A1 (also known as AE1), which mediates chloride-bicarbonate exchange in the basolateral membrane of type A intercalated cells (exchange of chloride into intercalated cells and bicarbonate into plasma), and SLC4A4 (also known as NBC1), which mediates sodium-bicarbonate co-transport in renal proximal tubule cells $[46,48]$.

These renal chloride carriers are key components of suggested models for physicochemical renal acid-base regulation [46]. Figure 2 shows an example of such regulation across proximal tubule cells. Physicochemical modelling of distal renal tubular acidosis from mutation of SLC4A1 (AE1) and proximal renal tubular acidosis from mutation of SLC4A4 (NBC1) [49] has also consolidated the argument for the Stewart approach. This renal tubular acidosis modelling focuses on renal net handling of $\mathrm{Na}^{+}, \mathrm{K}^{+}$and $\mathrm{Cl}^{-}$, the SID constituents, which means that chloride movement is no longer secondary to bicarbonate changes. In another physicochemical viewpoint, a departure from the conventional explanation of ammonium ion $\mathrm{NH}_{4}^{+}$as a carrier of $\mathrm{H}^{+}$has been proposed [50]. $\mathrm{NH}_{4}^{+}$should instead be seen as a weak cation that, by co-excretion with chloride, allows loss of chloride without sodium or potassium.

\section{Disorders of chloraemia and manipulation of chloride in the ICU}

Hyperchloraemia or hypochloraemia, resulting from disease processes or clinical manipulations, is common in 


\begin{tabular}{l} 
Table 4. Conditions associated with hypochloraemia in the \\
intensive care unit \\
\hline Chloride loss \\
Diuretic therapy \\
Significant gastric drainage \\
Vomiting \\
Chronic respiratory acidosis \\
Water gain in excess of chloride \\
Congestive cardiac failure \\
Syndrome of inappropriate ADH secretion \\
Excessive infusion of hypotonic solutions
\end{tabular}

the ICU (see Tables 4 and 5), and should always be seen in relation to sodium. Hyperchloraemia with hypernatraemia, or hypochloraemia with hyponatraemia, will not change the SID and thus will not affect the acid-base balance.

Intravenous administration of chloride-rich fluids is probably the most common and modifiable cause of hyperchloraemia in the ICU. The chloride content of these fluids, from $0.9 \% \mathrm{NaCl}$ (saline) to the various colloids suspended in saline (Tables 1 and 2), is supraphysiologic [51], with significant hyperchloraemia following the administration of such fluids in volunteers [13,52], intraoperatively $[9,10,12,14,15,30]$ or as cardiopulmonary bypass prime fluid [11].

While saline was a life-saving measure when first introduced during the cholera pandemic of Europe in the $1830 \mathrm{~s}$ [53], it is to be noted that the saline used then was of a different composition. A reconstitution of the Thomas Latta solution revealed a sodium concentration of $134 \mathrm{mmol} / \mathrm{l}$, chloride $118 \mathrm{mmol} / \mathrm{l}$ and bicarbonate $16 \mathrm{mmol} / \mathrm{l}$. The historical or scientific basis of the present-day $0.9 \%$ composition of saline remains a mystery, even when traced to those cholera pandemic days that marked the beginning of the intravenous fluid technique and its various solutions [54]. On the other hand, there appears to be common lack of basic knowledge for optimal fluid and electrolyte prescription. Intravenous fluid and electrolyte prescriptions in postoperative surgical patients vary widely, with $0.9 \%$ saline being most common, and show poor correlation between serum electrolyte values and the amounts of electrolytes prescribed [55]. Moreover, less than one-half of prescribers in 25 different surgical units were aware of the sodium content of $0.9 \%$ saline [56]. Chloride-rich fluids result in acidosis and evidence from animal studies, particularly in sepsis, point to a possible association with negative outcomes.

\section{Chloride and resuscitation of sepsis}

Fluid resuscitation is a mainstay for the treatment of severe sepsis. The recognition of hyperchloraemic strong
Table 5. Conditions associated with hyperchloraemia in the intensive care unit

Chloride infusion
Administration of chloride-rich fluids
Total parenteral nutrition
Pure water loss
Skin losses
Fever
Hypermetabolic states
Renal losses
Central diabetes insipidus
Nephrogenic diabetes insipidus
Water loss in excess of chloride loss
Extrarenal loss
Diarrhoea
Burns
Renal loss
Osmotic diuresis
Post-obstructive diuresis
Intrinsic renal disease
Definite or relative increase in tubular chloride reabsorption
Renal tubular acidosis
Recovery of diabetic ketoacidosis
Early renal failure
Acetazolamide
Ureteral diversion procedures
Post hypocapnia

ion acidosis has led to the reconsideration of the impact of intravenous fluid contents in septic patients.

In anaesthetized dogs infused with endotoxin, high chloride saline infusion given to maintain mean arterial pressure $>80 \mathrm{mmHg}$ increased serum chloride and accounted for $42 \%$ of the total acid load [57], significantly greater than the contribution by lactate. When comparing saline resuscitation with Hextend $^{\circledR}$ (hydroxyethyl starch (HES) in balanced solution; BioTime Inc., Berkeley, CA, USA) in a rat model of septic shock, investigators reported significantly lower standard base excess and SID and a lower mean survival time with saline [58].

In an animal study of the effects of hyperchloraemic acidosis from saline, the degree of systemic hypotension correlated significantly with the increase in plasma chloride levels [59], a stronger correlation than with $\mathrm{pH}$. A significant increase was also seen in plasma nitrite levels in the saline group; in cell cultures, however, hyperchloraemic acidosis was found to be proinflammatory, inducing nitric oxide release, increased IL-6:IL-10 ratios and increased NF-kB DNA binding [60]. In a second 
animal study, after controlling for hypotension, there was a significant increase in cytokines with hyperchloraemic acidosis - greater increases were seen with more severe acidosis [61].

Therefore it would seem prudent to avoid chloride-rich fluids in sepsis despite controversy on whether acidosis results in physiological injury or is just a side effect of illness [62]. At present, the best evidence for acidosisinduced organ injury is mainly from animal studies [63,64] thus making any specific recommendation difficult.

\section{Hyperchloraemia and renal function}

Animal studies offer insight into the role of chloride in regulating renal blood flow. In denervated dog kidneys, intrarenal infusion of chloride-containing solutions produced renal vasoconstriction and a fall in the glomerular filtration rate [65]. This observation was specific for renal vessels, and the investigators proposed tubular chloride reabsorption as a key initiating step, based on similarities with the tubuloglomerular feedback mechanism, also initiated by chloride reabsorption [66]. This tubuloglomerular feedback is a regulation of the glomerular filtration rate, which begins with chloride detection at the macula densa and ends with mesangial contraction reducing the glomerular filtration rate. Increased chloride re-absorption through a $\mathrm{Na} / \mathrm{K} / 2 \mathrm{Cl}$ transporter activates the release of ATP for mesangial contraction [67]. In another animal study, the same group found that thromboxane may mediate chloride-induced vasoconstriction [68]. Another possible explanation for the phenomenon of hyperchloraemic renal vasoconstriction is the effect of chloride on renal responsiveness to vasoconstrictor agents. A study of the isolated rat kidney showed that continuous perfusion with high chloride progressively increased renal vascular responsiveness to angiotensin II [69]. A more comprehensive understanding of the vasoconstriction mechanisms, including probable interaction between chloride and other ions like calcium, could be on the horizon given the recent progress in chloride channels mentioned earlier.

Studies on human volunteers and patients support the above observations. A longer time to first micturition was observed with saline compared with a lactated solution in a crossover trial with human volunteers [70]. This observation was replicated in another human volunteer study, also with greater diuresis and natriuresis in the lactated solution group [52]. While the shorter time to micturition and greater diuresis could be attributed to the lower osmolality of the lactated solution causing decreased antidiuretic hormone secretion, the greater natriuresis suggests a specific chloride effect on the glomerular filtration rate.

Of further interest to ICU practice is the comparison of high-chloride fluids and low-chloride fluids during surgery. In older patients undergoing major surgery, a lower chloride load from a lactated solution or $6 \%$ hetastarch in balanced solution (Hextend ${ }^{\circ}$ ) again led to greater urine output compared with $0.9 \%$ saline and with $6 \%$ hetastarch in $0.9 \%$ saline [14]. A comparable study in older cardiac surgery patients revealed that the lower chloride group treated with balanced 6\% HES 130/0.42 plus a balanced crystalloid solution had significantly lower urinary concentrations of kidney-specific markers of injury - namely glutathione transferase alpha and neutrophil gelatinase-associated lipocalin - when measured up to the second postoperative day in the ICU [71].

In patients with renal dysfunction, many believe the risk of hyperkalaemia is greater with potassium-containing fluids like lactated solutions, thus leading to significantly higher use of $0.9 \%$ saline [72]. In contradiction to this paradigm, a randomized double-blind trial comparing lactated Ringer's solution and $0.9 \%$ saline during renal transplantation revealed a higher incidence of hyperkalaemia in the $0.9 \%$ saline group instead of in the lactated Ringer's solution group. The incidence of metabolic acidosis was also higher in the $0.9 \%$ saline group [73]. The authors suggested that hyperkalaemia was secondary to extracellular potassium shift due to hyperchloraemic (low-SID) acidosis.

\section{Chloride and splanchnic perfusion}

The above crossover trial comparing $0.9 \%$ saline with the lactated Ringer's solution in human volunteers also found a higher incidence of abdominal discomfort with saline [70]. This raised questions about splanchnic perfusion. In a study of older patients undergoing major surgery, the saline group had a higher postoperative gastric tonometric carbon dioxide gap, suggesting reduced gastric mucosal perfusion [14]. This study, although not powered to show a difference, also showed a significant trend towards increased nausea and vomiting in the saline group. While chloride's link to this phenomenon is unclear, it is interesting to note that a report of ammonium chloride poisoning referred to similar signs of nausea, vomiting and abdominal pain [74]. Animal studies, meanwhile, have demonstrated acidosis-induced intestinal injury [64] and impaired gastric-pyloric motility [75]. These findings warrant further investigation to define the role of chloride in the modulation of splanchnic perfusion.

\section{Chloride and haemostasis}

In a swine model of massive haemorrhage [76] comparing resuscitation with $0.9 \%$ saline, Ringer's lactate, Plasmalyte A and Plasmalyte R, investigators found that - apart from a significant decrease in acidosis with Ringer's lactate, Plasmalyte A and Plasmalyte R - Ringer's lactate also achieved a trend towards a higher survival rate. A decade later, in a rat model of massive haemorrhage, resuscitation 
with red blood cells and Ringer's lactate solution produced a significantly better acid-base balance and significantly greater 2 -week survival than resuscitation with red blood cells and $0.9 \%$ saline [77]. The hyperchloraemic acidosis seen with $0.9 \%$ saline resuscitation has also been highlighted as an easily preventable iatrogenic cause of acidosis in trauma resuscitation [78].

Hyperchloraemic acidosis has also been suggested as part of the explanation for increased blood loss, increased requirement for blood and blood products, and coagulation abnormalities in patients receiving 0.9\% saline or HES suspended in saline $[15,79,80]$. In a randomized trial comparing Hextend ${ }^{\circ}$ (a $6 \%$ HES in a balanced solution) with 6\% HES in saline, trends toward less bleeding were seen in the Hextend ${ }^{\circ}$ group. The HES in saline group further showed significant prolongation of time to onset of clot formation on thromboelastography, an effect not seen in the Hextend ${ }^{\circ}$ group [79]. Another randomized trial comparing $0.9 \%$ saline against lactated Ringer's solution for patients undergoing abdominal aortic aneurysm demonstrated a similar pattern. The saline group received significantly more blood products and had a trend towards increased blood loss [15]. In another comparison of 6\% HES in balanced vehicle against 6\% HES in saline during major surgery, a hypocoagulable state (confirmed by significantly abnormal thromboelastography) was seen in HES in saline [80]. Apart from its high chloride concentration, the lack of calcium in saline is another explanation for saline's worse haemostatic profile as shown in these trials.

There have also been a number of experimental studies on healthy volunteers predominantly looking at the difference between HES in saline and HES in balanced solutions [81-83]. All studies used thromboelastography to assess coagulation, and one study used whole blood aggregometry to assess platelet function. A similar trend toward hypocoagulation with HES in saline was seen. Haemodilution with HES in saline also resulted in reduced aggregometry. While HES itself is known to affect coagulation and thromboelastography, recent changes to its physicochemical characteristics, especially molar substitution, has minimized this effect. The solvent and its electrolyte composition might thus have contributed to hypocoagulability.

\section{Chloride in the ICU: the research agenda}

The growing body of knowledge presented above highlights the need to re-evaluate our perception of chloride in critical care. Clinically, there is a need to reevaluate our intravenous fluid practice, the patients' main source of external chloride. The evidence that the choice of fluids will affect the acid-base balance and could cause a host of other potentially undesirable physiological alterations, as described above, is difficult to ignore.
More importantly, all of this preliminary evidence leads to a number of research questions that are pertinent to chloride and the care of ICU patients. How common is hyperchloraemia in the ICU? Is hyperchloraemia an independent predictor of death or other adverse outcomes? Or does hyperchloraemia only matter when associated with SID changes or acidaemia? Can the elimination of chloride-rich fluids lead to clinical benefits? We consider these to be questions that need urgent attention given the millions of litres of saline and the millions of millimoles of excess chloride administered to patients worldwide every day.

\section{Conclusions}

Chloride has been forgotten for too long. Better knowledge of its molecular functions, driven by new findings of the structure, molecular biology and physiology of its channels, and better understanding of the clinical effects of chloride loading, indicate that alterations in the chloride balance and chloraemia, both absolute and relative to natraemia, can alter the acid-base status, cell biology, renal function and haemostasis. The clinical consequences of these biological and physiological alterations remain unclear. The observation that most of these alterations appear to have negative implications and the knowledge that high-chloride fluids are administered to large numbers of patients worldwide, however, suggest the need to conduct formal investigations into the epidemiology and outcome implications of disorders of chloride balance and chloride concentration.

\section{Abbreviations}

GABA, Y-aminobutyric acid; HES, hydroxyethyl starch; ICU, intensive care unit; IL, interleukin; ISF, interstitial fluid; NF, nuclear factor; SID, strong ion difference; SLC, solute carrier.

\section{Competing interests}

The authors declare that they have no competing interests.

\section{Author details}

'Department of Intensive Care, Austin Hospital, Heidelberg, Melbourne, VIC 3084, Australia. 'Department of Anaesthesia, Austin Hospital, Heidelberg, Melbourne, VIC 3084, Australia. ${ }^{3}$ Department of Critical Care Medicine, University of Pittsburgh Medical Center, Pittsburgh, PA 15261, USA.

\section{Published: 8 July 2010}

References

1. Ganong WF: Review of Medical Physiology. 22nd edition. New York: McGraw Hill; 2005.

2. PubMed [http://www.ncbi.nlm.nih.gov/pubmed]

3 Kellum JA: Acid-base physiology in the post-Copernican area. Curr Opin Crit Care 1999, 5:429-435.

4. Cushing $\mathrm{H}$ : Concerning the poisonous effect of pure sodium chloride solutions upon nerve-muscle preparation. Am J Physiol 1901, 6:77-90.

5. Odaira T: The influence of some neutral salt solutions, intravenously administered, on the reserve alkali of the blood. Tohoku J Exp Med 1923, 4:523-526

6. Shires GT, Holman J: Dilution acidosis. Ann Intern Med 1948, 28:557-559.

7. Black DAK: Body fluid depletion. Lancet 1953, 261: 305-311.

8. McFarlane C, Lee A: A comparison of Plasmalyte 148 and $0.9 \%$ saline for intra-operative fluid replacement. Anaesthesia 1994, 49:779-781. 
9. Scheingraber S, Rehm M, Sehmisch C, Finsterer U: Rapid saline infusion produces hyperchloraemic acidosis in patients undergoing gynecologic surgery. Anesthesiology 1999, 90:1265-1270.

10. Waters JH, Miller LR, Clack S, Kim JV: Cause of metabolic acidosis in prolonged surgery. Crit Care Med 1999, 27:2142-2146.

11. Liskaser FJ, Bellomo R, Hayhoe M, Story D, Poustie S, Smith B, Letis A, Bennett $M$ : The role of pump prime in the etiology and pathogenesis of cardiopulmonary bypass-associated acidosis. Anesthesiology 2000, 93:1170-1173.

12. Rehm M, Orth V, Scheingraber S, Kreimeier U, Brechtelsbauer H, Finsterer U: Acid-base changes due to $5 \%$ albumin versus $6 \%$ hydroxyethylstarch solution in patients undergoing acute normovolemic hemodilution: a randomized prospective study. Anesthesiology 2000, 93:1174-1183.

13. Waters JH, Bernstein CA: Dilutional acidosis following hetastarch or albumin in healthy volunteers. Anesthesiology 2000, 93:1184-1187.

14. Wilkes NJ, Woolf R, Mutch M, Mallett SV, Peachey T, Stephens R, Mythen MG The effects of balanced versus saline-based hetastarch and crystalloid solutions on acid-base and electrolyte status and gastric mucosal perfusion in elderly surgical patients. Anesth Analg 2001, 93:811-816.

15. Waters JH, Gottlieb A, Schoenwald P, Popovic MJ, Sprung J, Nelson DR: Normal saline versus lactated Ringer's solution for intraoperative fluid management in patients undergoing abdominal aortic aneurysm repair: an outcome study. Anesth Analg 2001, 93:817-822.

16. Stewart PA: How to Understand Acid-Base. A Quantitative Primer for Biology and Medicine. New York: Elsevier; 1981

17. Stewart PA: Modern quantitative acid-base chemistry. Can J Physiol Pharmacol 1983, 61:1444-1461.

18. Klemtz K, Ho L, Bellomo R: Daily intravenous chloride load and the acidbase and biochemical status of intensive care unit patients. J Pharm Pract Res 2008, 38:296-299

19. Jentsch TJ: Chloride channels are different. Nature 2002, 415:276-277.

20. Dutzler R, Campbell EB, Cadene M, Chait BT, Mackinnon R: X-ray structure of a CIC channel at $3.0 \AA$ reveals the molecular basis of anion selectivity. Nature 2002, 415:287-294.

21. Jentsch TJ, Stein V, Weinreich F, Zdebik AA: Molecular structure and physiological function of chloride channels. Physiol Rev 2002, 82:503-568.

22. Food and Nutrition Board, Institute of Medicine of the National Academies: Dietary Reference Intakes for Water, Potassium, Sodium, Chloride, and Sulfate. Washington, DC: National Academies Press; 2004.

23. Schultz SG: The internal environment. In Essential Medical Physiology. 3rd edition. Edited by Johnson LR, Byrne JH. San Diego: Academic Press; 2003:4-6.

24. Koch SM, Taylor RW: Chloride ion in intensive care medicine. Crit Care Med 1992, 20:227-240

25. Morimatsu H, Rocktaschel J, Bellomo R, Uchino S, Goldsmith D, Gutteridge G: Comparison of point-of-care versus central laboratory measurement of electrolyte concentrations on calculations of the anion gap and the strong ion difference. Anesthesiology 2003, 98:1077-1084.

26. Story D, Morimatsu H, Egi M, Bellomo R: The effect of albumin concentration on plasma sodium and chloride measurements in critically ill patients. Anesth Analg 2007, 104:893-897.

27. Figge J, Jabor A, Kazda A, Fencl V: Anion gap and hypoalbuminemia. Crit Care Med 1998, 26:1807-1810.

28. Kellum JA, Kramer DJ, Pinsky MR: Strong ion gap: a methodology for exploring unexplained anions. J Crit Care 1995, 10:51-55.

29. Story D, Morimatsu H, Bellomo R: Strong-ions, weak-acids, and base-excess: a simplified Fencl-Stewart approach to clinical acid-base disorders. $\mathrm{Br} J$ Anaesth 2004, 92:54-60.

30. Boldt J, Schollhorn T, Munchbach J, Pabsdorf M: A total balanced volume replacement strategy using a new balanced hydroxyethyl starch preparation (6\% HES 130/0.42) in patients undergoing major abdominal surgery. Eur J Anaesthesiol 2007, 24:267-275.

31. Story DA, Morimatsu H, Bellomo R: Hyperchloraemic acidosis in the critically ill: one of the strong-ion acidoses? Anesth Analg 2006, 103:144-148.

32. Rocktaeschel J, Morimatsu H, Uchino S, Bellomo R: Unmeasured anions in critically ill patients: can they predict mortality? Crit Care Med 2003, 31:2131-2136

33. Antinoni B, Piva S, Paltenghi M, Candiani A, Latronico N: The early phase of critical illness is a progressive acidic state due to unmeasured anions. Eur 」 Anaesthesiol 2008, 25:566-572.

34. Story DA: Hyperchloraemic acidosis: another misnomer? Crit Care Resusc 2004, 6:188-192.
35. Alfaro V, Torras R, Ibanez J, Palacios L: A physical-chemical analysis of the acid-base response to chronic obstructive pulmonary disease. Can J Physiol Pharmacol 1996, 74:1229-1235.

36. Levitin $\mathrm{H}$, Branscome W, Epstein FH: The pathogenesis of hypochloremia in respiratory acidosis. J Clin Invest 1958, 37:1667-1675.

37. Verkman AS, Galietta JV: Chloride channels as drug targets. Nat Rev Drug Discov 2009, 8:153-171.

38. Pusch M: Myotonia caused by mutations in the muscle chloride channel gene CLCN1. Hum Mut 2002, 19:423-434

39. Haug K, Warnstedt M, Alekov AK, Sander T, Ramirez A, Poser B, Maljevic S, Hebeisen S, Kubisch C, Rebstock J, Horvath S, Hallman K, Dullinger JS, Rau B, Haverkamp F, Beyenburg S, Schulz H, Janz D, Giese B, Müller-Newen G, Propping P, Elger CE, Fahlke C, Lerche H, Heils A: Mutations in CLCN2 encoding a voltage-gated chloride channel are associated with idiopathic generalized epilepsies. Nat Genet 2003, 33:527-532.

40. Crowell MD, Harris LA, DiBaise JK, Olden KW: Activation of type-2 chloride channels: a novel therapeutic target for the treatment of chronic constipation. Curr Opin Investig Drugs 2007, 8:66-70.

41. Okada Y, Shimizu T, Maeno E, Tanabe S, Wang X, Takahashi N: Volumesensitive chloride channels involved in apoptotic volume decrease and cell death. J Membrane Biol 2006, 209:21-29.

42. Pinheiro da Silva F, Nizet V: Cell death during sepsis: integration of disintegration in the inflammatory response to overwhelming infection. Apoptosis 2009, 14:509-521.

43. Barret KE: Gastrointestinal Physiology. New York: McGraw-Hill; 2006.

44. Barret KE, Keely SJ: Chloride secretion by the intestinal epithelium: molecular basis and regulatory aspects. Annu Rev Physiol 2000, 62:535-572.

45. Guyton AC, Hall JE: Textbook of Medical Physiology. 11th edition. Philadelphia: Elsevier Sanders: 2006

46. Corey HE: Renal acid-base physiology. In Critical Care Nephrology. 2nd edition. Edited by Ronco C, Bellomo R, Kellum JA. Philadelphia: Elsevier Sanders; 2009:587-592.

47. Sindic A, Chang MH, Mount DB, Romero MF: Renal physiology of SLC26 anion exchangers. Curr Opin Nephrol Hypertens 2007, 16:484-490.

48. Romero MF: Molecular pathophysiology of SLC4 bicarbonate transporters. Curr Opin Nephrol Hypertens 2005, 14:495-501

49. Ring T, Frische S, Nielsen S: Clinical review: renal tubular acidosis a physicochemical approach. Crit Care 2005, 9:573-580.

50. Kellum JA: Determinants of plasma acid-base balance. Crit Care Clin 2005, 21:329-346.

51. Wakim KG:' Normal' $0.9 \%$ salt solution is neither'normal' nor physiological [letter]. JAMA 1970, 214:1710

52. Reid F, Lobo DN, Williams RN, Rowlands BJ, Allison SP: (Ab)normal saline and physiological Hartmann's solution: a randomized double-blind crossover study. Clin Sci 2003, 104:17-24

53. Latta T: Malignant cholera. Lancet 1831-1832, ii:274-277.

54. Awad S, Allison SP, Lobo DN: The history of $0.9 \%$ saline. Clin Nutr 2008, 27:179-188.

55. Stoneham MD, Hill EL: Variability in post-operative fluid and electrolyte prescription. Br J Clin Pract 1997, 51:82-84.

56. Lobo DN, Dube MG, Neal KR, Simpson JS, Rowlands BJ, Allison SP. Problems with solutions: drowning in the brine of an inadequate knowledge base. Clin Nutr 2001, 20:125-130.

57. Kellum JA, Bellomo R, Kramer DJ, Pinsky MR: Etiology of metabolic acidosis during saline resuscitation in endotoxaemia. Shock 1998, 9:364-368.

58. Kellum JA: Fluid resuscitation and hyperchloraemic acidosis in experimental sepsis: improved short-term survival and acid-base balance with Hextend compared with saline. Crit Care Med 2002, 30:300-305.

59. Kellum JA, Song M, Venkataraman R: Effects of hyperchloraemic acidosis on arterial pressure and circulating inflammatory molecules in experimental sepsis. Chest 2004, 125:243-248

60. Kellum JA, Song M, Li J: Lactic and hydrochloric acids induce different patterns of inflammatory response in LPS-stimulated RAW 264.7 cells. Am J Physiol Regul Integr Comp Physiol 2004, 286:686-692.

61. Kellum JA, Song M, Almasri E: Hyperchloraemic acidosis increases circulating inflammatory molecules in experimental sepsis. Chest 2006, 130:962-967.

62. Kellum JA: Metabolic acidosis in patients with sepsis: epiphenomenon or part of the pathophysiology? Crit Care Resusc 2004, 6:197-203.

63. Pedoto A, Caruso JE, Nandi J: Acidosis stimulates nitric oxide production and lung damage in rats. Am J Respir Crit Care Med 1999, 159:397-402. 
64. Pedoto A, Nandi J, Oler A, Camporesi AM, Hakim TS, Levine RA: Role of nitric oxide in acidosis-induced intestinal injury in anaesthetized rats. $\mathrm{L}$ Lab Clin Med 2001, 138:270-276.

65. Wilcox CS: Regulation of renal blood flow by plasma chloride. J Clin Invest 1983, 71:726-735

66. Schnermann J, Ploth DW, Hermle M: Activation of tubuloglomerular feedback by chloride transport. Pfluegers Arch Eur J Physiol 1976, 362:229-240.

67. Eaton D, Pooler J: Vander's Renal Physiology. 7th edition. New York: McGraw-Hill Medical; 2009.

68. Bullivant EMA, Wilcox CS, Welch WJ: Intrarenal vasoconstriction during hyperchloraemia: role of thromboxane. Am J Physio/ 1989, 256:152-157.

69. Quilley CP, Lin YS, McGiff JC: Chloride anion concentration as a determinant of renal vascular responsiveness to vasoconstrictor agents. Br J Pharmacol 1993, 108:106-110.

70. Williams EL, Hildebrand KL, McCormick SA, Bedel MJ: The effect of intravenous lactated Ringer's solution versus $0.9 \%$ sodium chloride solution on serum osmolality in human volunteers. Anesth Analg 1999. 88:999-1003.

71. Boldt J, Suttner S, Brosch C, Lehmann A, Rohm K, Mengistu A: The influence of a balanced volume replacement concept on inflammation, endothelial activation, and kidney integrity in elderly cardiac surgery patients. Intensive Care Med 2009, 35:462-470.

72. O'Malley CMN, Frumento RJ, Bennett-Guerrero E: Intravenous fluid therapy in renal transplant recipients: results of a U.S. survey. Transplant Proc 2002, 34:3142-3145.

73. O'Malley CMN, Frumento RJ, Hardy MA, Benvenisty Al, Brentjens TE, Mercer JS, Bennett-Guerrero E: A randomized, double-blind comparison of lactated Ringer's solution and $0.9 \% \mathrm{NaCl}$ during renal transplantation. Anesth Analg 2005, 100:1518-1524.

74. Mythen MG, Hamilton MA: Hyperchloremic metabolic acidosis: is it clinically relevant? Transfus Altern Transfus Med 2001, 4:15-19.

75. Tournadre JP, Allaouchiche B, Malbert CH, Chassard D: Metabolic acidosis and respiratory acidosis impair gastro-pyloric motility in anesthetized pigs. Anesth Analg 2000, 90:74-79.
76. Traverso LW, Lee WP, Langford MJ: Fluid resuscitation after an otherwise fatal hemorrhage: I. Crystalloid solutions. J Trauma 1986, 26:168-175.

77. Healey MA, Davis R, Liu FC, Loomis WH, Hoyt DB: Lactated Ringer's is superior to normal saline in a model of massive hemorrhage and resuscitation. J Trauma 1998, 45:894-899.

78. Ho AM-H, Karmakar KM, Contardi LH, Ng SW, Hewson JR: Excessive use of normal saline in managing traumatized patients in shock: a preventable contributor to acidosis. J Trauma 2001, 51:173-177.

79. Gan TJ, Bennett-Guerrero E, Phillips-Bute B, Wakeling H, Moskowitz DM, Olufolabi Y, Konstadt SN, Bradford C, Glass PSA, Machin SJ, Mythen MG; Hextend ${ }^{\circledR}$ Study Group: Hextend ${ }^{\circledR}$, a physiologically balanced plasma expander for large volume use in major surgery: a randomized phase III clinical trial. Anesth Analg 1999, 88:992-998.

80. Martin G, Bennett-Guererro E, Wakeling H, Mythen MG, El-Moalem H, Robertson K, Kucmeroski D, Gan TJ: A prospective, randomized comparison of thromboelastographic coagulation profile in patients receiving lactated Ringer's solution, $6 \%$ hetastarch in a balanced-saline vehicle, or $6 \%$ hetastarch in saline during major surgery. J Cardiothorac Vasc Anesth 2002, 16:441-446

81. Roche AM, James MFM, Grocott MPW, Mythen MG: Coagulation effects of in vitro serial haemodilution with a balanced electrolyte hetastarch solution compared with a saline-based hetastarch solution and lactated Ringer's solution. Anaesthesia 2002, 57:950-955

82. Roche AM, James MFM, Bennett-Guerrero E, Mythen MG: A head-to-head comparison of the in vitro coagulation effects of saline-based and balanced electrolyte crystalloid and colloid intravenous fluids. Anesth Analg 2006, 102:1274-1279.

83. Boldt J, Wolf M, Mengistu A: A new plasma-adapted hydroxyethylstarch preparation: in vitro coagulation studies using thromboelastography and whole blood aggregometry. Anesth Analg 2007, 104:425-430.

doi:10.1186/cc9052

Cite this article as: Mohd Yunos N, et al:: Bench-to-bedside review: Chloride in critical illness. Critical Care 2010, 14:226. 